\title{
Bench Scale Study of Coating Formulations for Abatement of Mercury Vapor and Recovery of Mercury Spills
}

Don Fox

Rick Demmer

Stephen Reese

February 2018

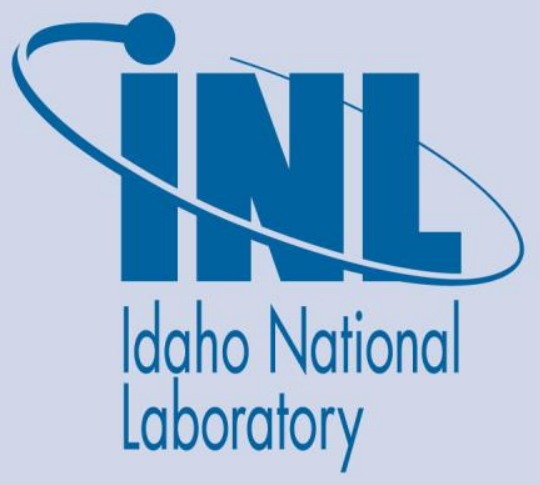

The INL is a U.S. Department of Energy National Laboratory operated by Battelle Energy Alliance 


\section{DISCLAIMER}

This information was prepared as an account of work sponsored by an agency of the U.S. Government. Neither the U.S. Government nor any agency thereof, nor any of their employees, makes any warranty, expressed or implied, or assumes any legal liability or responsibility for the accuracy, completeness, or usefulness, of any information, apparatus, product, or process disclosed, or represents that its use would not infringe privately owned rights. References herein to any specific commercial product, process, or service by trade name, trade mark, manufacturer, or otherwise, does not necessarily constitute or imply its endorsement, recommendation, or favoring by the U.S. Government or any agency thereof. The views and opinions of authors expressed herein do not necessarily state or reflect those of the U.S. Government or any agency thereof. 


\title{
Bench Scale Study of Coating Formulations for Abatement of Mercury Vapor and Recovery of Mercury Spills
}

\author{
Don Fox, Rick Demmer, Stephen Reese
}

February 2018

Idaho National Laboratory Idaho Falls, Idaho 83415

http://www.inl.gov

Prepared for the

U.S. Department of Energy

Office of Environmental Management

Under DOE Idaho Operations Office

Contract DE-AC07-05ID14517 
INTENTIONALLY BLANK 


\section{SUMMARY}

A sealant formulation has been developed that effectively mitigates human exposure to elemental mercury vapor evolving from spilled mercury. The sealant may be dispensed using a fogging methodology (for industrial settings) or a common spray bottle (for home or school settings). In parallel, the potential for $\mathrm{Hg}$ recovery using strippable coatings was evaluated.

Four liquid coatings were evaluated: one fogging fixative (FX2) developed at INL for the containment of surface and airborne contamination and three commercially available strippable decontamination gels (Carboset 441, Encor 449, and Stripcoat TLC Free).

Bench scale mercury vapor abatement tests were conducted in an enclosure using FX2 with the addition of a mercury absorbent and a mercury reactant. Testing with FX2 showed the reactant contributed significantly to reducing the rate of mercury evaporation. The reactant had a minimal impact on the mercury evaporation rate for the strippable coatings. The potential of strippable coatings to remove/recover mercury was inferred from the adhesive and cohesive performance of sprayable dilutions of the coatings applied to porous and non-porous surfaces.

Testing provided the following results:

- Mercury vapor concentration was reduced by a factor of 40 using the reactant enhanced FX2 solution, as well as with dilutions of Carboset and Encor. Dilute Stripcoat was less effective at reducing $\mathrm{Hg}$ evaporation.

- A $100 \times$ reduction in $\mathrm{Hg}$ evaporation rate was achieved using a coating of $\mathrm{FX}+$ the $\mathrm{Hg}$ reactant (a.k.a. FX Hg), compared to uncoated $\mathrm{Hg}$.

- A $2 \times$ reduction in the $\mathrm{Hg}$ vapor accumulation rate was achieved using $\mathrm{FX} \mathrm{Hg}$, compared to the strippable coatings.

- Strippability and adhesion tests show that dilutions of Carboset and Stripcoat can be stripped from a variety of indoor surfaces. Dilute Encor was not strippable.

Results suggest FX $\mathrm{Hg}$ and dilute Carboset will likely reduce $\mathrm{Hg}$ vapor concentrations, in an indoor setting, to a level at or below the Occupational Safety and Health Administration 8-hour human exposure limit $\left(0.1 \mathrm{mg} / \mathrm{m}^{3}\right)$. FX Hg dispensed via fogging would increase worker safety during remediation and demolition of industrial facilities with high levels of elemental mercury contamination. When applied via spray bottle, FX Hg may provide a safe and convenient method for the mitigation of $\mathrm{Hg}$ vapor in residential or commercial settings (e.g., offices, homes, schools). This approach would be most beneficial where recovery of the spilled $\mathrm{Hg}$ is impractical.

A sprayed then stripped application of dilute Carboset may provide a safe and convenient method for recovery of small $\mathrm{Hg}$ spills in residential and commercial settings. Further testing is required to determine if liquid $\mathrm{Hg}$ sufficiently adheres to the strippable coating to be recovered in this way. If it can be dispensed as a fog, dilute Carboset could be employed to recover $\mathrm{Hg}$ contamination in industrial settings. Testing of the foggability of dilute Carboset is required to assess this potential. 
INTENTIONALLY BLANK 


\section{CONTENTS}

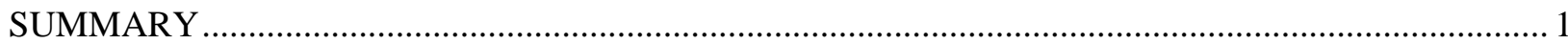

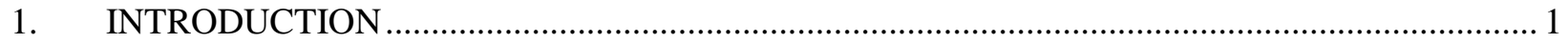

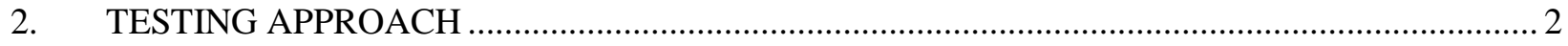

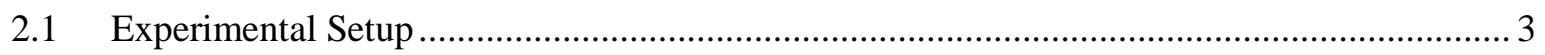

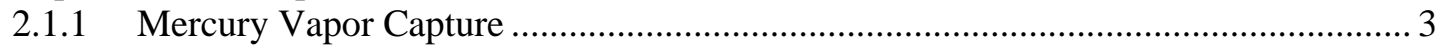

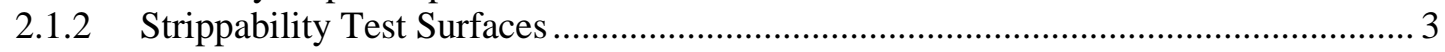

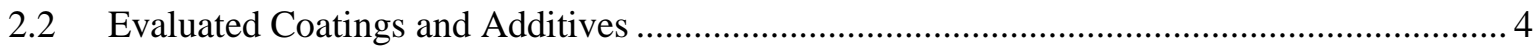

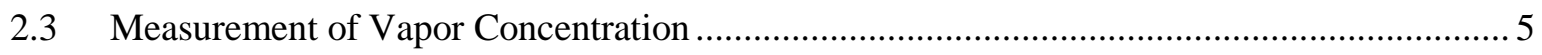

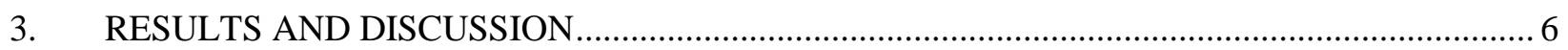

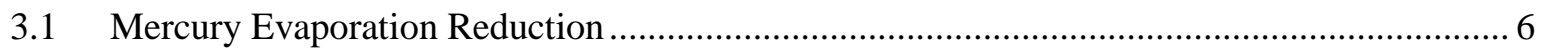

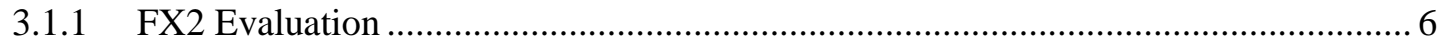

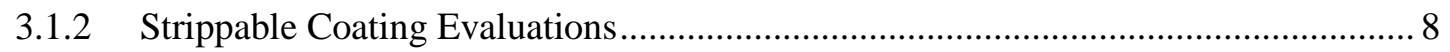

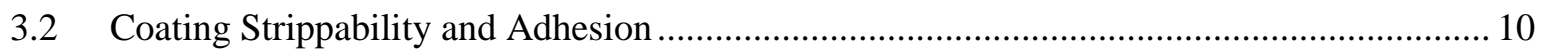

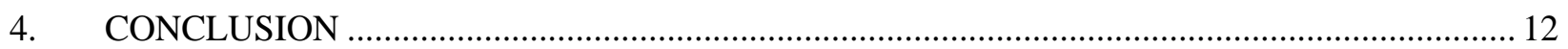

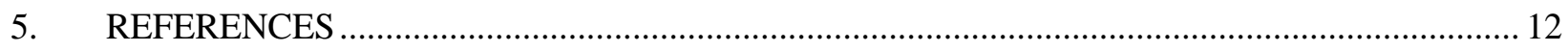

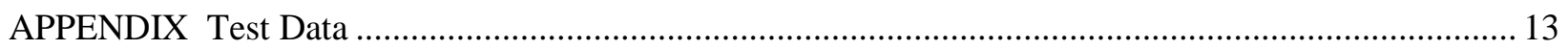

FIGURES

Figure 1. Frequency of elemental (liquid) Hg contamination at EPA National Priorities listed

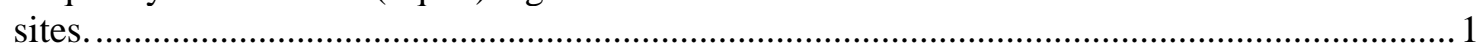

Figure 2. Experimental setup for $\mathrm{Hg}$ vapor abatement tests. ............................................................. 3

Figure 3. Evaluation of $\mathrm{Hg}$ vapor reduction for various FX2 formulations, including the uncoated,

Hg-only base case ..................................................................................................... 7

Figure 4. Final images of (A) FX2 only coating and (B) FX2 + Additive 1 (a.k.a. FX Hg) coating........... 8

Figure $5 . \mathrm{Hg}$ vapor reduction for evaluated commercial coatings. ....................................................... 8

Figure 6. Hg aliquots coated with (A) Carboset, (B) Carboset + Additive 1, (C) Encor, and (D) Encor + Additive 1, after 57, 80, 79, and 57 hours drying time, respectively...........................

Figure 7. Examples of good and poor strippability performance: (A) good strippability of dilute Carboset from a nonporous, plastic surface, and (B) the loss of strippability of dilute Encor from a porous concrete surface.

Figure 8. Examples of Carboset strippability from porous surfaces: (A) on an undulating granite surface and (B) on a smooth concrete surface.

Figure 9. Examples of Stripcoat TLC Free strippability from porous surfaces: (A) on an undulating granite surface and (B) on a smooth concrete surface. 


\section{TABLES}

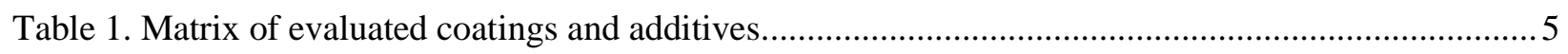

Table 2. Hg vapor diffusion rates for FX2 additives over the first 24 hours after coating. ...................... 7

Table 3. Strippable coatings' $\mathrm{Hg}$ vapor diffusion rates over the first 24 hours after coating. ....................9 
INTENTIONALLY BLANK 
INTENTIONALLY BLANK 


\section{INTRODUCTION}

In the broadest sense, liquid mercury $(\mathrm{Hg})$ contaminated sites present a hazard to both humans and the environment. There are 714 liquid $\mathrm{Hg}$ contaminated sites in the United States $-49 \%$ of the 1,467 hazardous waste sites on the U.S. Environmental Protection Agency's (EPA) National Priorities List. ${ }^{[1]}$ The distribution of identified $\mathrm{Hg}$ contaminated sites is shown in Figure 1. Clearly, the extent of $\mathrm{Hg}$ contamination in the United States is large, and the need for remediation is considered a priority by the U.S. EPA.

In industrial, residential, and commercial settings, accidental $\mathrm{Hg}$ spills can produce concentrations of $\mathrm{Hg}$ vapor in indoor air that are poisonous to adults and can be lethal to children. The most recent estimate indicates that about 152,000 people are potentially exposed to $\mathrm{Hg}$ vapor in workplace environments in the United States. ${ }^{[1]}$ Industrial exposure to $\mathrm{Hg}$ vapor occurs from $\mathrm{Hg}$ incorporated into manufacturing processes (such as the production of chlorine gas, Portland cement, caustic soda, sulfuric acid, automobile sensors and switches, liquid crystal displays, dry cell batteries, measurement and control devices, fluorescent and $\mathrm{Hg}$ vapor lamps, and disposal/recycling of $\mathrm{Hg}$ and $\mathrm{Hg}$ contaminated items). ${ }^{[2]} \mathrm{In}$ commercial and residential settings, adults and children are exposed to $\mathrm{Hg}$ vapor when $\mathrm{Hg}$ containing items (such as fluorescent lamps, blood pressure cuffs, barometers, and fever thermometers) are broken.

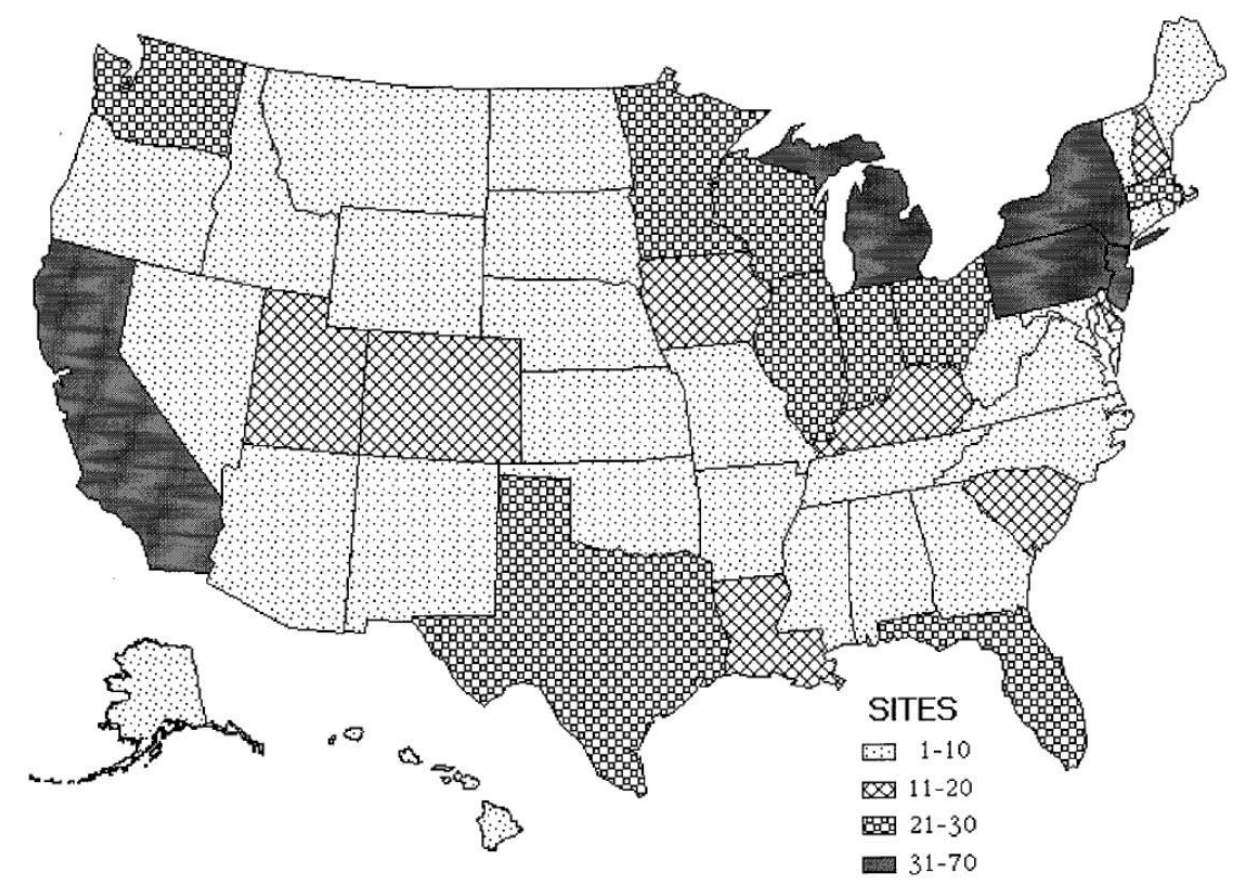

Figure 1. Frequency of elemental (liquid) $\mathrm{Hg}$ contamination at EPA National Priorities listed sites.

Kits are available for decontamination of small $\mathrm{Hg}$ spills in accessible locations (e.g., breakage of a compact fluorescent light bulb on nonporous flooring), and larger spills may be recovered by specially equipped workers using a sophisticated vacuum system. However, the use of vacuum recovery may increase the spread of $\mathrm{Hg}$ vapor, and not all spills are easily recoverable because of the materials and locations involved. For these reasons, the need exists for mitigation of human exposure to $\mathrm{Hg}$ vapor resulting from:

- Prolonged $\mathrm{Hg}$ recovery efforts,

- Containment of non-recoverable $\mathrm{Hg}$ spills,

- Contaminated facility demolition efforts. 
In this study, the potential uses of sprayable/foggable coatings for $\mathrm{Hg}$ vapor abatement and/or $\mathrm{Hg}$ recovery were investigated as a cost-effective alternative to current decontamination methods.

Mercury in any of its three forms (i.e., elemental, inorganic, organic) is highly toxic to humans, affecting the neurologic, gastrointestinal, and renal organ systems. ${ }^{[1]}$ The pathway of human exposure to $\mathrm{Hg}$ depends on which form of $\mathrm{Hg}$ is considered. This study considers the elemental (i.e., liquid) form of $\mathrm{Hg}$ and inhalation of $\mathrm{Hg}$ vapor, by liquid $\mathrm{Hg}$ evaporation, as the exposure pathway. The main objective of this study is to provide a basic formulation for sealants (i.e., coatings) that:

1. Effectively mitigates human exposure to $\mathrm{Hg}$ vapor, and

2. May be employed in industrial and commercial/residential settings, using a fogging methodology or a common spray bottle, respectively.

Because of $\mathrm{Hg}$ 's relatively high vapor pressure $\left(0.002 \mathrm{~mm} \mathrm{Hg}\right.$ at $\left.25^{\circ} \mathrm{C}\right),{ }^{[3]}$ toxic levels of $\mathrm{Hg}$ vapor can accumulate rapidly in indoor air following a liquid $\mathrm{Hg}$ spill. Prompt action is necessary to prevent elevated vapor concentrations and prolonged human exposure following even a small $\mathrm{Hg}$ spill. Complete recovery of spilled $\mathrm{Hg}$ is desirable to avoid prolonged exposure to $\mathrm{Hg}$ vapor; however, $\mathrm{Hg}$ is heavy and small beads readily sink into floor cracks and disperse into inaccessible places. Therefore, recovery can be a challenge for even small $\mathrm{Hg}$ spills (e.g., the amount in one thermometer). When recovery efforts require prolonged worker exposure to $\mathrm{Hg}$ vapor, development of a coating and application methodology that minimizes $\mathrm{Hg}$ evaporation would be beneficial. If recovery is impractical due to location and/or the surface involved, use of coatings for in-place containment could provide a cost-effective alternative to recovery.

\section{TESTING APPROACH}

This study evaluates the effectiveness of three strippable coatings and one fixative coating for reduction of $\mathrm{Hg}$ evaporation under indoor conditions. The four coatings under evaluation include three commercial, strippable decontamination solutions (Carboset 441, Encor 449, and Stripcoat TLC Free) and INL's proprietary fogging fixative (FX2). The commercial coatings were formulated for recovery of loose contaminants from minimally porous surfaces by peeling the dried (i.e., cured) sealant as a cohesive film from surfaces, with contaminants adhering to the film. FX2 was developed for in-place containment of loose contaminants on surfaces, porous and nonporous.

The overall goal is to provide a formulation for coatings that can be applied in a fogging application at the industrial scale and in a hand-sprayer application in the home or school setting. The consistency of each strippable coating was adjusted (by water dilution) to be approximately compatible with the fogging process developed for FX2 ${ }^{[4]}$ A second objective of this study was to evaluate the potential for liquid $\mathrm{Hg}$ recovery using strippable coatings, based on their adhesive and cohesive nature. Coating formulations that performed well relative to $\mathrm{Hg}$ vapor abatement were selected for additional formula optimization and fogging application studies.

The ability of dilute coating formulations to reduce $\mathrm{Hg}$ evaporation was evaluated by applying the coating to an aliquot of $\mathrm{Hg}$ in an enclosure. The subsequent equilibrium concentration of $\mathrm{Hg}$ vapor in the enclosure was used to indicate reduction of $\mathrm{Hg}$ evaporation relative to the vapor concentration achieved without a coating (i.e., the base case). Tests were conducted to establish performance of each coating without additives. Additional tests incorporating a $\mathrm{Hg}$ absorbent and/or $\mathrm{Hg}$ reactant were conducted. Equilibrium $\mathrm{Hg}$ vapor concentrations recorded for all coating formulations were compared to the Occupational Safety and Health Administration (OSHA) permissible exposure limit for $\mathrm{Hg}$ vapor in air $\left(0.1 \mathrm{mg} / \mathrm{m}^{3}\right) .^{[5]}$

Liquid $\mathrm{Hg}$ recovery was not quantified in this study. The potential for $\mathrm{Hg}$ recovery was based on the adhesive and cohesive nature of the three strippable coatings evaluated. Recovery potential is inferred from evaluations of the adhesion and strippability (i.e., the ease with which cured sealants are peeled by 
hand), relative to porous and nonporous construction materials. Recovery tests using small $\mathrm{Hg}$ beads consistent with a spill would be appropriate for the most promising coatings.

\subsection{Experimental Setup}

\subsubsection{Mercury Vapor Capture}

Figure 2 shows the experimental setup used in this study. The experimental enclosure consisted of a pyramid type glove bag (Captair, model 2200ANM) that has butyl rubber gloves, a port for gas sampling, and an approximate internal volume of $0.07 \mathrm{~m} 3$. The enclosure was placed in a fume hood for evacuation of $\mathrm{Hg}$ vapors between tests. A vinyl tube $(0.3 \mathrm{~cm} \mathrm{ID})$ was routed through the gas sampling port with the open end suspended $20 \mathrm{~cm}$ above the $\mathrm{Hg}$ aliquot and the opposing end connected to an $\mathrm{Hg}$ vapor analyzer (described in Section 2.3). A consistent $0.2 \mathrm{~mL}$ aliquot (2.7 g, assuming $\mathrm{Hg}$ density of $13.53 \mathrm{~g} / \mathrm{ml}$ ) of liquid $\mathrm{Hg}$ (Sigma-Aldrich) was used for all tests. Aliquots were measured and dispensed using a $1 \mathrm{~mL}$ hypodermic syringe. Aliquots were placed in a plastic cup lined with Glad Cling Wrap (see the insets in Figure 2). A glass Petri dish was used for secondary containment. $0.5 \mathrm{~mL}$ of each coating was applied to $\mathrm{Hg}$ aliquots via a $1 \mathrm{~mL}$ syringe. $0.5 \mathrm{~mL}$ was sufficient to fully cover an aliquot.

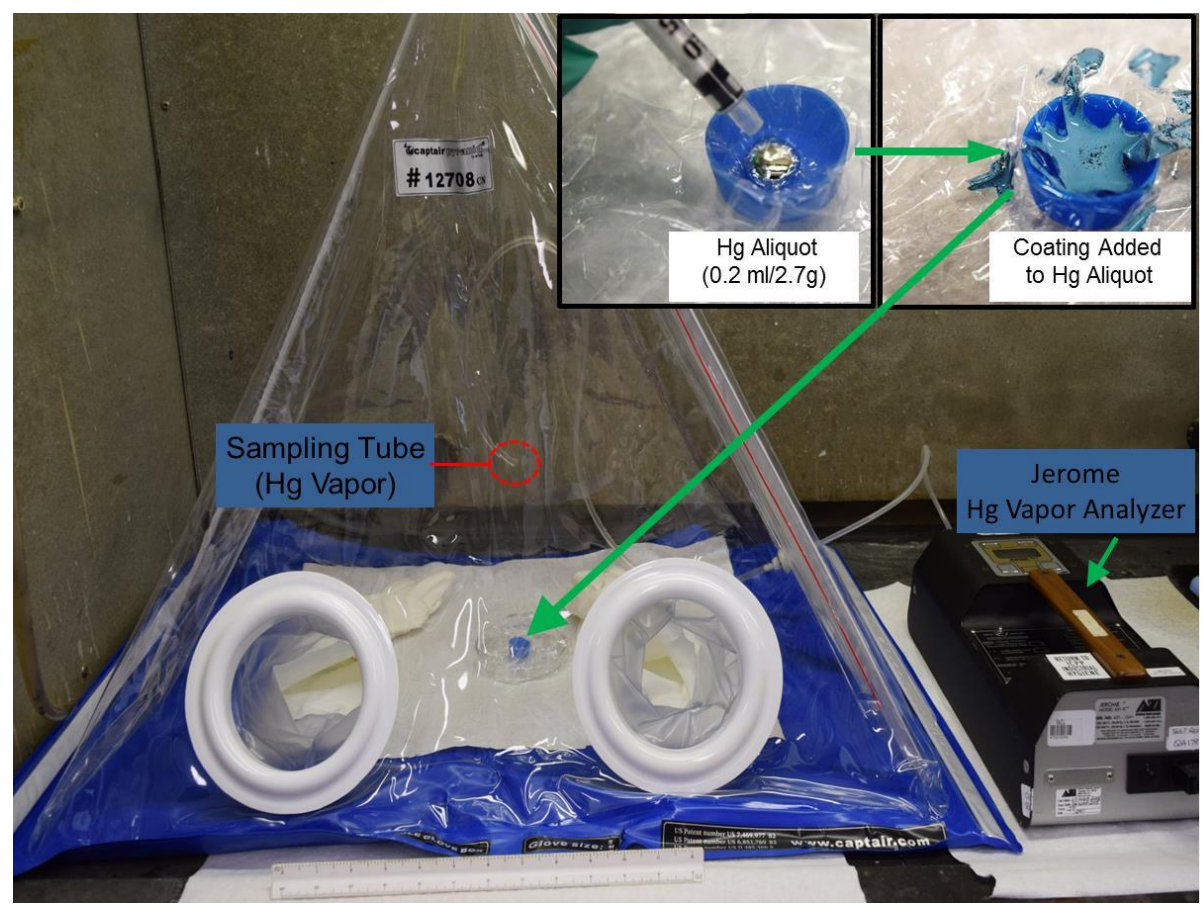

Figure 2. Experimental setup for $\mathrm{Hg}$ vapor abatement tests.

Vapor abatement tests were conducted at ambient laboratory temperature $\left(16\right.$ to $\left.26^{\circ} \mathrm{C}\right)$. Laboratory temperatures were documented using an ERTCO (Germany) model 1328 thermometer. Relative humidity in the laboratory was not documented, but a range of 16 to $80 \%$ (48\% average) was recorded during the test period by the National Weather Service station at the Idaho Falls Regional Airport, approximately $52 \mathrm{~km}$ east of the laboratory.

\subsubsection{Strippability Test Surfaces}

The strippable coatings under evaluation were originally formulated for recovery of loose surface contaminants. The dried coating adheres to particles and peels from the surface as a cohesive film. It is acknowledged that adjusting the consistency of coatings (by water dilution) for use as a fogging agent may alter the adhesive and cohesive (i.e., strippable) characteristics of the coatings. As such, 
determination of adhesion and strippability, relative to porous and nonporous surfaces, was the first step taken in evaluation of their potential as a fogged coating for $\mathrm{Hg}$ removal.

Materials used for strippability evaluations include:

- Plastic weigh pans $(4 \times 4$ in.), representing a smooth, nonporous surface

- Concrete coupons $(6 \times 6$ in.), representing a flat, porous surface

- Granite coupons $(6 \times 6$ in.), representing an uneven, porous surface

\subsection{Evaluated Coatings and Additives}

The strippable coatings were too viscous to be sprayed using a common hand operated spray bottle. Dilutions were made using $18 \mathrm{M} \Omega$ water. Sprayability was determined to be adequate when a mist visually comparable to that of FX2, with minimal splatter, was obtained using the spray bottle. Future viscosity testing and formula optimization are suggested for development of solutions as fogging agents.

The coatings used in this study are as follows:

1. FX2 - A solution of latex paint, glycerol, and sodium lauryl sulfate in water that was developed at INL as a non-strippable fogging agent for containment of surface and airborne contaminants. In these tests, FX2 was made with blue tinted paint to improve visibility. The FX2 consistency is optimized for fogging application; no additional dilution was required for these tests.

2. Stripcoat TLC Free (TLC Sanchem, Inc., Chicago, Illinois) - Stripcoat TLC Free is a yellow tinted strippable coating that is formulated for removal of radiological and chemical particles from indoor contaminated surfaces. A 33\% water dilution (i.e., two parts Stripcoat to one part water) was used to make Stripcoat sprayable.

3. Carboset 441 (Lubrizol Corp., Sheffield Village, Ohio) - Carboset is a strippable coating that was formulated for protection of metal (i.e., nonporous) surfaces. A $20 \%$ water dilution (i.e., four parts Carboset to one part water) was used to make Carboset sprayable.

4. Encor 449 (Arkema, Inc., King of Prussia, Pennsylvania) - Encor is a strippable coating that was formulated for protection of metal (nonporous) surfaces. A $40 \%$ water dilution (i.e., three parts Encor to two parts water) was used to make Encor sprayable.

Chemicals were added to the coatings to evaluate their ability to absorb and/or react with the mercury. Mercury absorbers were added to the coating solutions to reduce $\mathrm{Hg}$ diffusion to the coating's free surface (i.e., the coating-atmosphere interface). Mercury reactants were added to the coating solutions to react with $\mathrm{Hg}$ to form a stable compound that does not evolve mercury vapor, thereby reducing the coating's permeability and $\mathrm{Hg}$ vapor diffusion to the coating's free surface. The solid additives were slowly stirred into solution, then vigorously stirred for 1 minute.

Absorbent and reactive additives tested:

- Additive 1 - Mercury reacting chemical, $\leq 150 \mu \mathrm{m}$ particle size, ASTM \#100 sieve.

- Additive 2 - Mercury absorbing chemical, sieved to a $\leq 25 \mu \mathrm{m}$ particle size using an ASTM \#500 sieve.

- $\quad$ Additive 3 - A combination of additives 1 and 2.

- $\quad$ Additive 4 - Mercury absorbing and reacting compound. 
- Additive 5 - Commercial mercury absorbing and reacting compound, sieved to a $\leq 25 \mu \mathrm{m}$ particle size using an ASTM \#500 sieve.

Additive concentration was held constant at $0.035 \mathrm{~g} / \mathrm{mL}$ ( $3.5 \mathrm{~g}$ per $100 \mathrm{~mL}$ solution). This concentration was selected based on observation of a concentration in solution that was sprayable as a relatively fine mist without plugging the spray nozzle. Additive 3 is the exception. Being a combination of additives 1 and 2 , the concentration of each chemical was maintained at $0.035 \mathrm{mg} / \mathrm{L}$, thus a total of $7.0 \mathrm{~g}$ of solids were added per $100 \mathrm{~mL}$ solution ( $7.0 \mathrm{wt}$. \% solid addition). These subjective amounts of solid additions form the basis for formula optimization tests. Based on results from initial evaluations with FX2, additive 1 was selected for evaluation with the strippable coatings. Table 1 is a matrix of coating solutions evaluated in this study.

Table 1. Matrix of evaluated coatings and additives.

\begin{tabular}{|c|c|c|c|c|c|c|}
\hline & \multicolumn{6}{|c|}{ Additives } \\
\hline Coating & No Additive & $\mathbf{1}$ & $\mathbf{2}$ & $\mathbf{3}$ & $\mathbf{4}$ & $\mathbf{5}$ \\
\hline FX2 & $\mathrm{X}$ & $\mathrm{X}$ & $\mathrm{X}$ & $\mathrm{X}$ & $\mathrm{X}$ & $\mathrm{X}$ \\
\hline Carboset & $\mathrm{X}$ & $\mathrm{X}$ & - & - & - & - \\
\hline Encor & $\mathrm{X}$ & $\mathrm{X}$ & - & - & - & - \\
\hline TLC & $\mathrm{X}$ & $\mathrm{X}$ & - & - & - & - \\
\hline
\end{tabular}

\subsection{Measurement of Vapor Concentration}

Evaluations of $\mathrm{Hg}$ vapor abatement were conducted in an enclosure. Evaporation in such an enclosure is expected to be an equilibrium process that can be defined simply by the ideal gas law for a unit volume:

$$
N=\frac{P}{R T}
$$

where:

$P=\mathrm{Hg}$ vapor pressure, $0.002 \mathrm{~mm} \mathrm{Hg}$ at $25^{\circ} \mathrm{C}(2.632 \mathrm{E}-06 \mathrm{~atm})$

$R=$ Universal gas constant, $0.08206 \mathrm{~L} \cdot \mathrm{atm} / \mathrm{K} \cdot \mathrm{mol}$

$T=$ Temperature in Kelvin, $298.15^{\circ} \mathrm{C}\left(25^{\circ} \mathrm{C}\right)$

$N=$ moles $/ \mathrm{L}$

This relation yields a calculated equilibrium $\mathrm{Hg}$ vapor concentration of $21.6 \mathrm{mg} / \mathrm{m}^{3}$ (2.6 ppm), using the molar mass of $\mathrm{Hg}(200.59 \mathrm{~g} / \mathrm{mol})$ for conversion of $N$ from moles $/ \mathrm{L}$ to $\mathrm{mg} / \mathrm{m}^{3}$.

Measurements of vapor concentration were performed using a Jerome 431-X portable Hg vapor analyzer (visible on the right side of Figure 2). The Jerome analyzer utilizes adsorption of $\mathrm{Hg}$ onto an internal gold foil, which alters the foil's electrical resistance relative to a reference gold foil. Prior to each day's measurements, adsorbed $\mathrm{Hg}$ was removed from the gold foil using an automatic regeneration function (i.e., electric heating of the foil) and the instrument zero was checked (ambient laboratory air was used as a zero reference). Additionally, prior to measurements, the enclosure's gloves were waved around for 30 seconds to eliminate potential sampling error caused by stratification of $\mathrm{Hg}$ vapor. The instrument has an accuracy of $65 \%$ at $100 \mathrm{mg} / \mathrm{m}^{3} \mathrm{Hg}$ and precision of $5 \% .{ }^{[6]}$ When vapor concentrations exceeded the instrument saturation limit, a 1 L gas syringe (Trajan Scientific Americas, Inc., Austin, Texas) was used to draw a gas sample from the enclosure via the gas port. Sample dilution was performed by drawing laboratory air into the syringe until a total volume of $1 \mathrm{~L}$ was contained. The dilute gas sample was injected into an evacuated 3 L Tedlar bag (CEL Scientific Corp., Santa Fe Springs, California), which was 
subsequently connected to the vapor analyzer for measurement of the dilute vapor concentration. Reported concentrations are adjusted for the dilution.

Calculated and measured equilibrium $\mathrm{Hg}$ vapor concentrations were in disagreement for uncoated $\mathrm{Hg}$ aliquots. Measured equilibrium concentrations were approximately $10 \times$ lower than the calculated equilibrium concentration of $21.6 \mathrm{mg} / \mathrm{m}^{3}$. The source of this disagreement was not determined, but is believed to be related to a scaling coefficient programmed into the analyzer's software. Because relative, not absolute, comparisons are needed to evaluate coating performance, the accuracy of concentration measurements is not critical to the purpose of this study. For the purpose of presenting vapor concentration data on the most likely (and most conservative, relative to meeting regulatory limits) concentration scale, all measured vapor concentrations reported were multiplied by 10 .

NOTE: Measurement precision was confirmed by two base case replicate tests that are not presented here.

\section{RESULTS AND DISCUSSION}

\subsection{Mercury Evaporation Reduction}

\subsubsection{FX2 Evaluation}

This study first evaluated FX2 with and without additives. Figure 3 shows $\mathrm{Hg}$ vapor concentrations in the enclosure for the base case (i.e., no coating) and the various formulations of FX2. The coatings demonstrated three advantages:

1. A reduction in the rate at which vapor concentration increases prior to achieving equilibrium in the enclosure (i.e., a more gentle slope on the initial portion of the vapor concentration curve);

2. A decline in the equilibrium concentration over time (i.e., the uncoated sample curve is flat once equilibrium is achieved, whereas the coated samples' curves show a gradual decline in equilibrium vapor concentration);

3. A reduction in the total mass of $\mathrm{Hg}$ evaporated, which is indicated by lower maximum vapor concentrations measured for the coated samples.

The inset in Figure 3 magnifies the lower portion of the graph, showing $\mathrm{Hg}$ vapor concentrations without the base case, in order to accentuate differences between the various FX2 formulations (see the Appendix for the complete datasets used to generate Figure 3).

Maximum vapor concentrations occurred within 24 hours for the base case and within approximately 24 to 48 hours for the various FX2 formulations. Relative to the base case, use of coatings resulted in a decrease in the rate of $\mathrm{Hg}$ vapor concentration increase. The evaporation rate (i.e., the rate of vapor diffusion across a coating's free surface) was calculated by fitting a linear expression to the first 24 hours of concentration measurements. Table 2 shows the calculated vapor diffusion rates (in $\mathrm{mg} / \mathrm{m}^{3} / \mathrm{hr}$ ) for each test series. The diffusion rate for FX2 + Additive $1\left(0.009 \mathrm{mg} / \mathrm{m}^{3} / \mathrm{hr}\right)$ was $100 \times$ lower than that of the base case $\left(0.915 \mathrm{mg} / \mathrm{m}^{3} / \mathrm{hr}\right)$ and significantly lower than that of FX2 with other additives. The calculated diffusion rate for the base case is conservative. The $\mathrm{R}^{2}$ value of 0.748 indicates a relatively poor fit. Based on the base case curve shown in Figure 3, fitting a linear expression to the first 12 hours of data would achieve a better fit and a considerably higher value for the diffusion rate.

Coating application resulted in maximum vapor concentrations that decline with time, unlike the base case concentration, which was relatively constant with time. For the base case, unabated $\mathrm{Hg}$ evaporation resulted in a rate of vapor replenishment that was greater than enclosure leakage. The coatings diminished $\mathrm{Hg}$ evaporation to a rate less than the rate of enclosure leakage.

The inset in Figure 3 shows FX2 only and FX2 + Additive 2 performed similarly in reducing $\mathrm{Hg}$ evaporation; however, greater reductions were achieved when additive 1 was added to the recipe (i.e., 
additive 3 is additive $1+$ additive 2). This outcome reveals the minimal contribution provided by additive 2 for the reduction of vapor diffusion through the coating. The figure also shows a reduction in maximum vapor concentration $>40 \times$ for the other four additives $\left(<0.5 \mathrm{mg} / \mathrm{m}^{3}\right)$, compared to the base case ( $>$ $21 \mathrm{mg} / \mathrm{m}^{3}$ ). Based on the irrelevance of additive 2, a $\mathrm{Hg}$ absorber, and the importance of additive 1 , a $\mathrm{Hg}$ reactant, to lower vapor concentration, additive 1 was selected as the best additive and the one to be included in the evaluation of strippable coatings. Additives 3, 4, and 5 were different combinations of $\mathrm{Hg}$ absorber and $\mathrm{Hg}$ reactant.

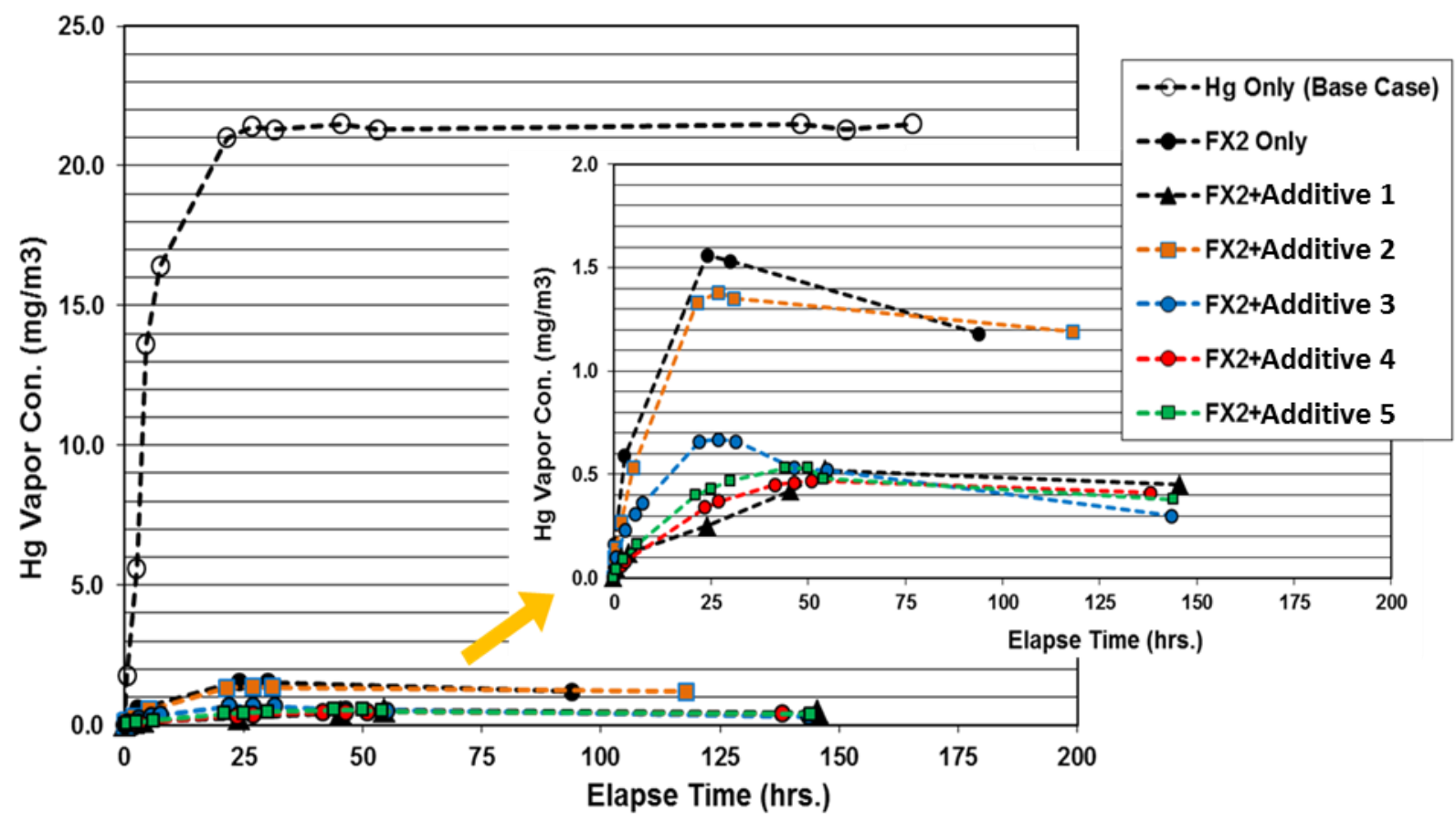

Figure 3. Evaluation of $\mathrm{Hg}$ vapor reduction for various FX2 formulations, including the uncoated, $\mathrm{Hg}$-only base case. The inset shows a magnification of the lower portion of the main graph, omitting the uncoated base case in order to accentuate differences between the various FX2 formulations.

Table 2. Hg vapor diffusion rates for FX2 additives over the first 24 hours after coating.

\begin{tabular}{|c|c|c|c|c|c|c|c|}
\hline & \multicolumn{7}{|c|}{ FX2 Additive } \\
\hline & $\begin{array}{c}\text { Hg Only } \\
\text { (Base Case) }\end{array}$ & $\begin{array}{c}\text { FX2 Only } \\
\text { (No Additive) }\end{array}$ & $\begin{array}{c}\text { Additive } \\
1\end{array}$ & $\begin{array}{c}\text { Additive } \\
2\end{array}$ & $\begin{array}{c}\text { Additive } \\
\mathbf{3}\end{array}$ & $\begin{array}{c}\text { Additive } \\
4\end{array}$ & $\begin{array}{c}\text { Additive } \\
5\end{array}$ \\
\hline Rate $\left(\mathrm{mg} / \mathrm{m}^{3} / \mathrm{hr}\right)$ & 0.915 & 0.061 & 0.009 & 0.058 & 0.027 & 0.014 & 0.017 \\
\hline $\mathrm{R}^{2(\mathrm{a})}$ & 0.748 & 0.935 & 0.862 & 0.974 & 0.922 & 0.987 & 0.985 \\
\hline
\end{tabular}

Figure 4 shows Hg aliquots coated with FX2 (at 94 hours) and FX2 + Additive 1 (at 150 hours). (Note: Cracks visible in the FX2 coating [left pane of Figure 4] occurred during handling and were not present during testing.) During drying, the FX2 + Additive 1 coating became black in color (right pane of Figure 4), as the additive reacted with $\mathrm{Hg}$. Formation of a solid, non-reactive $\mathrm{Hg}$ phase in the coating further inhibited $\mathrm{Hg}$ vapor diffusion through the coating, as indicated by the relatively low vapor diffusion rate of FX2 + Additive 1 (see Table 2). 

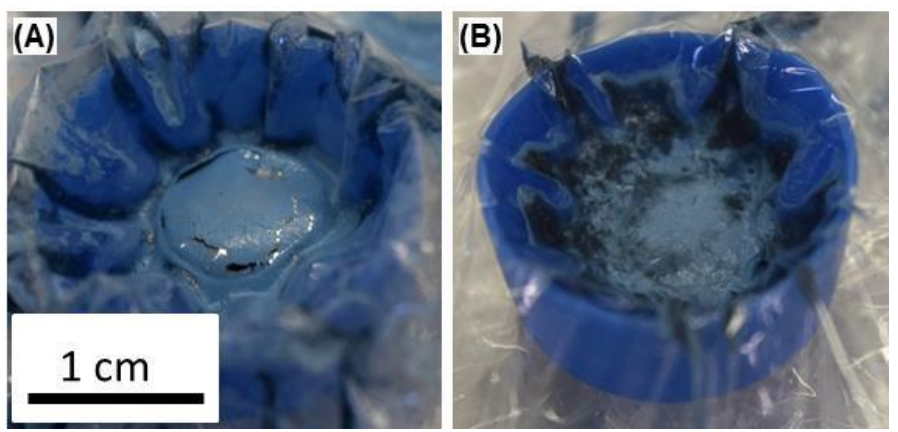

Figure 4. Final images of (A) FX2 only coating and (B) FX2 + Additive 1 (a.k.a. FX Hg) coating.

\subsubsection{Strippable Coating Evaluations}

Following tests with FX2, three strippable coatings (Carboset 441, Encor 449, and Stripcoat TLC Free) were evaluated. Figure 5 shows the evolution of $\mathrm{Hg}$ vapor concentrations in the enclosure for strippable coatings with and without the mercury reactant. Results for FX2 and FX2 + Additive 1 (a.k.a. FX Hg) are shown for comparison. (For the complete datasets used to generate Figure 5, see the Appendix.) Two primary results are evident from Figure 5 and Table 3:

1. Hg evaporation rates for Carboset and Encor are similar and clearly outperform Stripcoat TLC;

2. Hg vapor diffusion rates across the three strippable coatings were comparable and roughly $2 \times$ that of FX Hg (see Table 3).

Carboset and Encor formulations achieved maximum $\mathrm{Hg}$ vapor concentration $\left(\sim 0.5 \mathrm{mg} / \mathrm{m}^{3}\right)$ within approximately 24 hours. The maximum vapor concentration measured for Stripcoat was $\sim 1.2 \mathrm{mg} / \mathrm{m}^{3}$ at $\sim 76$ hours. Application of Stripcoat affected a $20 \times$ reduction of maximum vapor concentration.

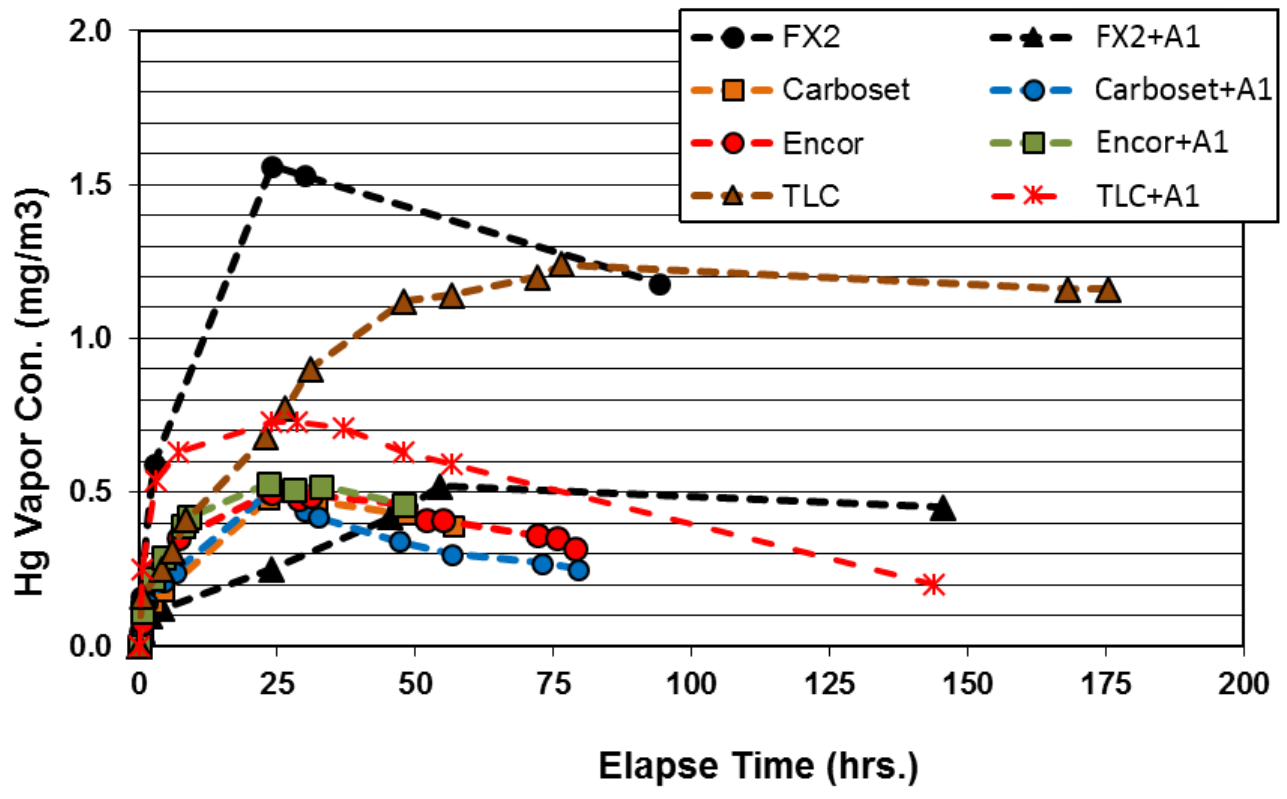

Figure $5 . \mathrm{Hg}$ vapor reduction for evaluated commercial coatings.

Table 3 shows vapor diffusion rates calculated by fitting a linear expression to the first 24 hours of vapor concentration measurements. Note the unreliable fit for the TLC + Additive 1 data due to the sharp rise 
and then round off of that curve in the first $\sim 12$ hours. Rates calculated for FX2 and FX Hg are repeated from Table 2 for comparison.

Table 3. Strippable coatings' Hg vapor diffusion rates over the first 24 hours after coating.

\begin{tabular}{|c|c|c|c|c|l|c|c|c|}
\hline & \multicolumn{7}{|c|}{ Coating } \\
\hline & FX2 & FX Hg & Carboset & Carboset+A1 & Encor & Encor+A1 & TLC & TLC+A1 \\
\hline Rate $\left(\mathrm{mg} / \mathrm{m}^{3} / \mathrm{hr}\right)$ & 0.061 & 0.009 & 0.019 & 0.019 & 0.018 & 0.020 & 0.026 & 0.022 \\
\hline $\mathrm{R}^{2}$ & 0.935 & 0.862 & 0.953 & 0.916 & 0.781 & 0.756 & 0.914 & 0.549 \\
\hline
\end{tabular}

Unlike FX2, the addition of the $\mathrm{Hg}$ reactant to Carboset and Encor contributed negligibly to the reduction of $\mathrm{Hg}$ evaporation, as indicated by the consistent $\sim 0.5 \mathrm{mg} / \mathrm{m}^{3}$ maximum measured vapor concentrations with and without the additive. The additive improves Stripcoat performance markedly, but the maximum vapor concentration remains larger than for Carboset and Encor. Figure 6 shows $\mathrm{Hg}$ aliquots coated with Carboset (after 57 hours), Carboset + Additive 1 (after 80 hours), Encor (after 79 hours), and Encor + Additive 1 (after 57 hours). Consistent with what was observed with FX Hg, strippable coatings containing the reactant became black in color (Figures $6 \mathrm{~b}$ and $6 \mathrm{~d}$ ) as the $\mathrm{Hg}$ stabilization reaction occurred. However, the rate of diffusion reduction achieved in $\mathrm{FX} \mathrm{Hg}$ was not achieved in Carboset and Encor. This outcome is likely due to the longer reaction time provided by FX Hg's $\sim 48$ hour drying time, compared to Carboset's and Encor's 24 hour drying time.
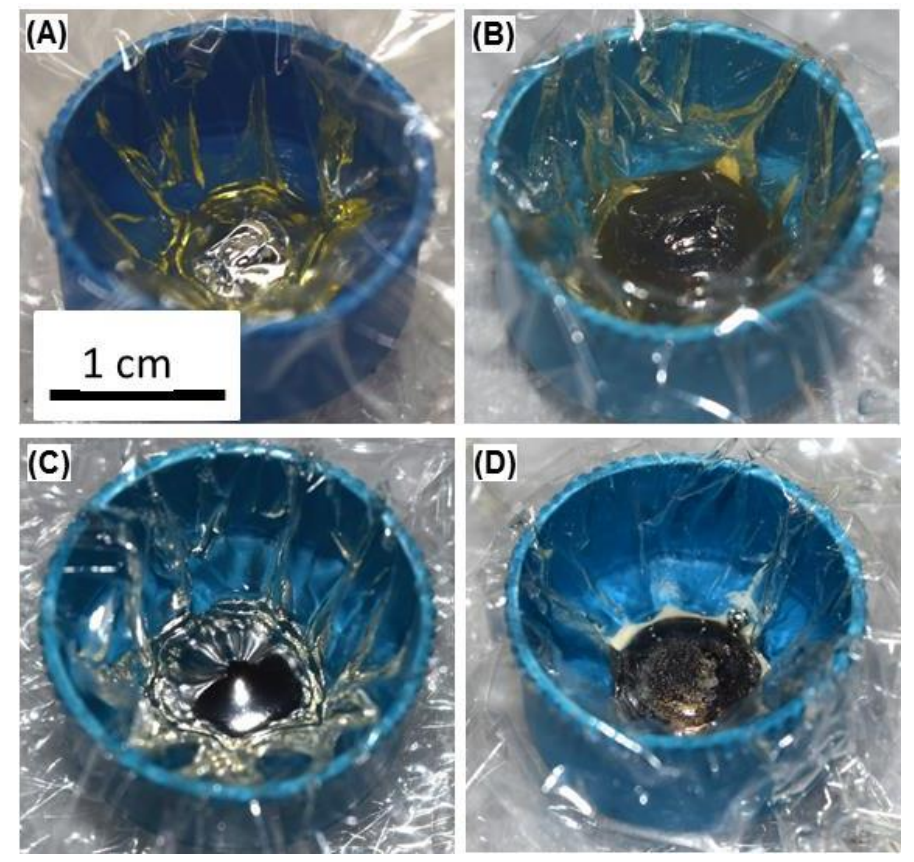

Figure 6. Hg aliquots coated with (A) Carboset, (B) Carboset + Additive 1, (C) Encor, and (D) Encor + Additive 1, after 57, 80, 79, and 57 hours drying time, respectively.

Although the maximum vapor concentrations measured for strippable coatings and FX $\mathrm{Hg}$ are consistent $\left(\sim 0.5 \mathrm{mg} / \mathrm{m}^{3}\right)$, the vapor diffusion rate of strippable coatings $\left(0.02 \mathrm{mg} / \mathrm{m}^{3} / \mathrm{hr}\right.$ on average $)$ is $2 \times$ greater than that of FX Hg $\left(0.009 \mathrm{mg} / \mathrm{m}^{3} / \mathrm{hr}\right)$. Following the initial use of an $\mathrm{Hg}$ vapor abatement coating in an indoor setting, knowledge of the vapor diffusion rate, as it relates to vapor accumulation, can provide guidance for follow-on actions. These actions may include planning of remediation efforts (e.g., ventilation rates, filter capacities, and personal protective equipment requirements) or determining the amount of time required for attenuation to reduce human exposure to a level permissible under regulatory laws. Currently, the OSHA limit for human exposure to airborne $\mathrm{Hg}$ is $0.1 \mathrm{mg} / \mathrm{m}^{3}$ over a weighted 8 hour 
period. Given a measurement period longer than the 3 to 4 days considered in this study, the $0.5 \mathrm{mg} / \mathrm{m}^{3}$ maximum vapor concentrations measured for the best performers in this study (FX Hg, Carboset 441, and Encor 449) would have most likely declined, due to enclosure leakage, to a level consistent with the OSHA limit $\left(0.1 \mathrm{mg} / \mathrm{m}^{3}\right)$. Further, vapor concentrations may have continued to decline to a level consistent with the more stringent $0.025 \mathrm{mg} / \mathrm{m}^{3}$ 8-hour exposure limit of the American Conference of Governmental Industrial Hygienists.

Based on the comparable 40x reduction in $\mathrm{Hg}$ evaporation of $\mathrm{FX} \mathrm{Hg}$, Carboset, and Encor, and on the $2 \times$ lower vapor diffusion rate of $\mathrm{FX} \mathrm{Hg}$, this study found the basic formulation of $\mathrm{FX} \mathrm{Hg}$ to be the best coating for $\mathrm{Hg}$ vapor abatement. Because of their comparable $\mathrm{Hg}$ evaporation reductions, optimization of dilute Carboset and Encor for fogging application and strippability is suggested. Evaluation of strippability is presented in the following subsection.

\subsection{Coating Strippability and Adhesion}

Student interns Jesse Viera and Janesler Gonzalez from FIU's DOE Fellows Program conducted tests on strippable coatings under consideration for $\mathrm{Hg}$ recovery. Water dilutions of Carboset, Encor, and Stripcoat were prepared (see Section 2.2) with no additional additives and applied, using a common spray bottle, to porous and nonporous coupons (see Section 2.1.2). Except on the nonporous surface, dilute coatings were applied in multiple layers per manufacturer recommendations. One thick application was applied to the nonporous surface (i.e., a plastic weighing pan). Because of surface porosity and subsequent fluid absorption, 15 layers of dilute Carboset and Encor were applied to the porous surface samples (i.e., granite and concrete) in order to obtain a thick and potentially strippable coating. Dilute Stripcoat frequently plugged the spray nozzle; therefore, a spatula was used to spread the bulk of the dilute Stripcoat onto the porous samples. It was noted that dilute Stripcoat is much more adhesive (i.e., sticky) than dilute Carboset and Encor. Fogged application of Stripcoat may not be possible, even with additional dilution. Coatings applied to plastic pans were allowed to dry overnight. Coatings applied to granite and concrete were dry to the touch within 4 hours, aided by fluid absorption into the porous surfaces.

Carboset, Encor, and Stripcoat were easily removed (i.e., stripped) from the nonporous surface as single cohesive pieces. However, after drying for approximately 48 hours, the Encor piece that was stripped from the plastic pan became very brittle. A similar result was observed for Encor on porous surfaces. Figure 7a provides an example of good nonporous surface strippability recorded for dilute Carboset. Figure $7 \mathrm{~b}$ shows the loss of cohesion (i.e., friability) seen for Encor on a concrete coupon. Dilute Carboset (Figure 8) and Stripcoat (Figure 9) maintained strippability and adhesive properties throughout porous and nonporous surface evaluations. Retained cohesion indicates that Carboset and Stripcoat will be strippable from a variety of indoor surfaces. Their adhesive properties suggest they have potential to retain embedded $\mathrm{Hg}$ when stripped from surfaces. 


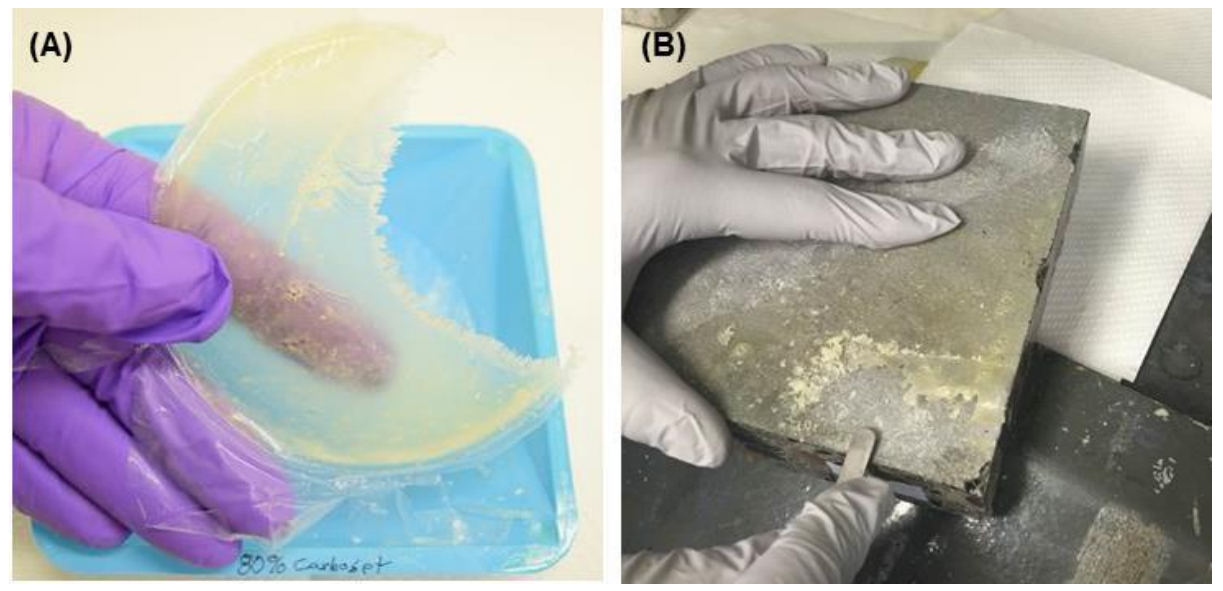

Figure 7. Examples of good and poor strippability performance: (A) good strippability of dilute Carboset from a nonporous, plastic surface, and (B) the loss of strippability of dilute Encor from a porous concrete surface. Note how the coating pictured in (B) crumbles instead of peeling as it is pried from the surface.
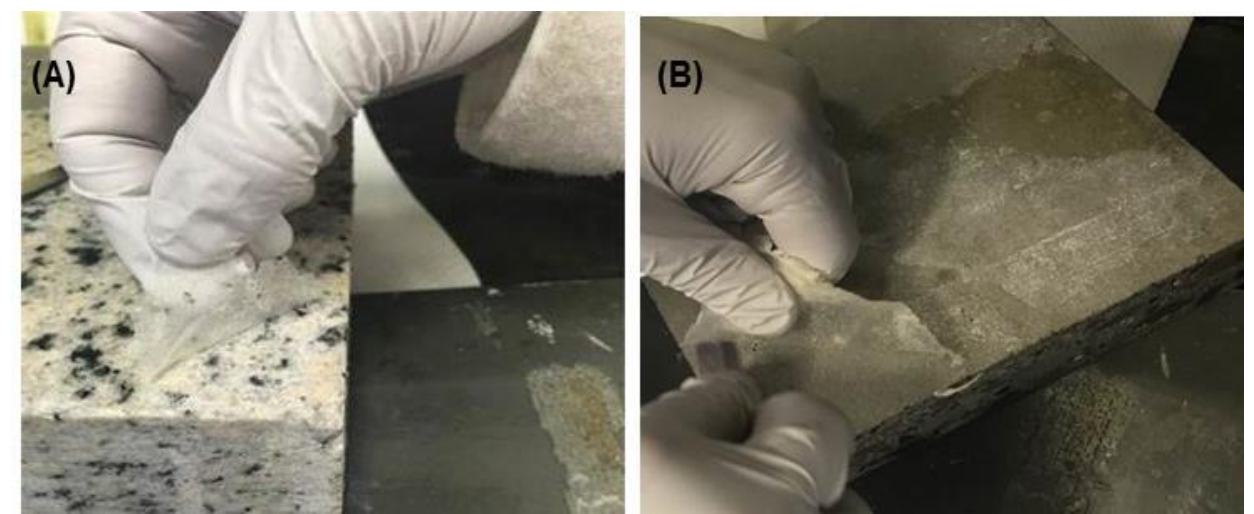

Figure 8. Examples of Carboset strippability from porous surfaces: (A) on an undulating granite surface and (B) on a smooth concrete surface.
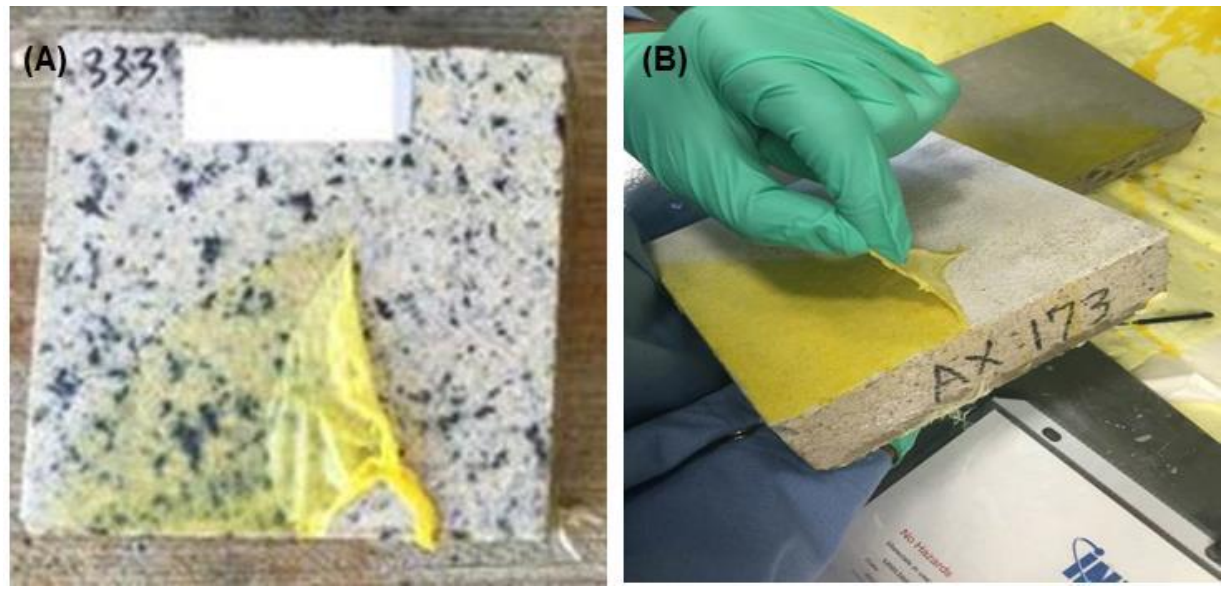

Figure 9. Examples of Stripcoat TLC Free strippability from porous surfaces: (A) on an undulating granite surface and (B) on a smooth concrete surface. 


\section{CONCLUSION}

Coatings of Carboset, Encor, and FX Hg reduced $\mathrm{Hg}$ evaporation equally well. The application of dilute Carboset, dilute Encor, or FX Hg effected a $>40 \times$ reduction of maximum vapor concentration in the enclosure (from $>21 \mathrm{mg} / \mathrm{m}^{3}$ without coating to $<0.5 \mathrm{mg} / \mathrm{m}^{3}$ with coating).

The time required for Carboset, Encor, and FX Hg coatings to cure was estimated to be the elapsed time between coating application and measurement of maximum vapor concentration. Cure times of $\sim 24$ hours for Carboset and Encor and $\sim 48$ hours for FX $\mathrm{Hg}$ were reported. Rudimentary calculations of $\mathrm{Hg}$ vapor diffusion rates through the coatings suggest that the additional cure time required for $\mathrm{FX} \mathrm{Hg}$ prolonged the intended $\mathrm{Hg}$ stabilization reaction, resulting in an $\mathrm{FX} \mathrm{Hg}$ coating that was less permeable to $\mathrm{Hg}$ vapor than the commercial coatings. The FX Hg mercury vapor diffusion rate $\left(0.009 \mathrm{mg} / \mathrm{m}^{3} / \mathrm{hr}\right)$ was $2 \times$ lower than the rates of Carboset and Encor $\left(\sim 0.019 \mathrm{mg} / \mathrm{m}^{3} / \mathrm{hr}\right)$ and was $100 \times$ less than the rate for uncoated $\mathrm{Hg}$ $\left(0.915 \mathrm{mg} / \mathrm{m}^{3} / \mathrm{hr}\right)$. FX2 has been extensively tested as a foggable agent for contamination control. As such $\mathrm{FX} \mathrm{Hg}$ is the most promising option for use a $\mathrm{Hg}$ fixative.

Regarding Hg recovery, dilute Carboset and Stripcoat maintained their cohesive and adhesive properties on porous and nonporous surfaces. Retained adhesion suggests Carboset and Stripcoat stripped from surfaces may retain embedded $\mathrm{Hg}$. Dilute Stripcoat proved difficult to dispense from a spray bottle, suggesting it may be difficult to apply via fogging or direct spraying. Further, Stripcoat did not perform as well as Carboset and Encor in reducing $\mathrm{Hg}$ evaporation. Dilute Carboset, on the other hand, is readily sprayable and significantly reduces $\mathrm{Hg}$ vapor concentration. Dilute Carboset is a good candidate for development as a foggable solution for $\mathrm{Hg}$ recovery.

\section{REFERENCES}

[1] Toxicological Profile For Mercury, U.S. Department of Health and Human Services, Public Health Service, Agency for Toxic Substances and Disease Registry, March 1999.

[2] Sources of Mercury in Industrial Facilities, http://www.glrppr.org/docs/mercury_in_industry.htm, accessed July 2015.

[3] Health Effects Notebook for Hazardous Air Pollutants - Mercury Compounds, https://www.epa.gov/sites/production/files/2016-09/documents/mercury-compounds.pdf, accessed February 2018.

[4] R.L. Demmer, D.T. Fox, and K.E. Archibald, "Pilot Scale Advanced Fogging Demonstration," INL/EXT-14-34022, January 2015.

[5] 29 CFR [Code of Federal Regulations] 1910.1000, revised 1 July 1999.

[6] Jerome 431-X Mercury Vapor Analyzer Operation Manual, Arizona Instrument LLC, Tempe, AZ, 2000. The Certificate of Instrument Calibration (ID 720924, 6/2/15) indicates a precision of $+/-5 \%$. 


\section{APPENDIX}

\section{Test Data}


Hg Only (base case)

\begin{tabular}{|c|c|c|c|c|c|c|}
\hline & Time & $\begin{array}{c}\text { Elapse } \\
\text { Time } \\
(\mathrm{hrs})\end{array}$ & $\begin{array}{c}\text { Measured } \\
\left(\mathrm{mg} \mathrm{Hg} / \mathrm{m}^{3}\right)\end{array}$ & Dilution & $\begin{array}{c}\mathrm{Hg} \\
\left(\mathrm{mg} / \mathrm{m}^{3}\right)\end{array}$ & Temp $\left({ }^{\circ} \mathrm{C}\right)$ \\
\hline $1 / 27 / 2015$ & $9: 30$ & 0 & 0.000 & 0 & 0.000 & 20.5 \\
\hline & $10: 00$ & 0.5 & 1.76 & 0 & 1.760 & 20.5 \\
\hline & $12: 00$ & 2.5 & 1.4 & 4 & 5.600 & 20.0 \\
\hline & $14: 00$ & 4.5 & 1.36 & 10 & 13.600 & 20.0 \\
\hline & $17: 00$ & 7.5 & 1.64 & 10 & 16.400 & 20.0 \\
\hline $1 / 28 / 2015$ & $7: 00$ & 21.5 & 2.10 & 10 & 21.000 & 20.0 \\
\hline & $12: 15$ & 26.75 & 2.14 & 10 & 21.400 & 20.0 \\
\hline & $17: 00$ & 31.5 & 2.13 & 10 & 21.300 & 20.0 \\
\hline $1 / 29 / 2015$ & $7: 00$ & 45.5 & 2.15 & 10 & 21.500 & 20.0 \\
\hline & $14: 30$ & 53.0 & 2.13 & 10 & 21.300 & 19.5 \\
\hline $2 / 2 / 2015$ & $7: 30$ & 142.0 & 2.15 & 10 & 21.500 & 20.0 \\
\hline & $17: 00$ & 151.5 & 2.13 & 10 & 21.300 & 20.0 \\
\hline $2 / 3 / 2015$ & $7: 00$ & 165.5 & 2.15 & 10 & 21.500 & 20.0 \\
\hline
\end{tabular}

FX2 Only (no additives)

\begin{tabular}{|c|c|c|c|c|c|c|}
\hline & Time & $\begin{array}{c}\text { Elapse } \\
\text { Time } \\
\text { Date }\end{array}$ & $\begin{array}{c}\text { Measured } \\
\left(\mathrm{mg} \mathrm{Hg} / \mathrm{m}^{3}\right)\end{array}$ & Dilution & $\begin{array}{c}\mathrm{Hg} \\
\left(\mathrm{mg} / \mathrm{m}^{3}\right)\end{array}$ & Temp $\left({ }^{\circ} \mathrm{C}\right)$ \\
\hline $10 / 8 / 2014$ & $10: 45$ & 0.0 & 0.000 & 0 & 0.000 & 18.0 \\
\hline $10 / 8 / 2014$ & $10: 48$ & 0.1 & 0.05 & 0 & 0.050 & 18.0 \\
\hline $10 / 8 / 2014$ & $11: 00$ & 0.3 & 0.16 & 0 & 0.160 & 18.0 \\
\hline $10 / 8 / 2014$ & $13: 30$ & 2.8 & 0.59 & 0 & 0.590 & 19.0 \\
\hline $10 / 9 / 2014$ & $10: 45$ & 24.0 & 1.56 & 0 & 1.560 & 19.5 \\
\hline $10 / 9 / 2014$ & $4: 45$ & 30.0 & 1.53 & 0 & 1.530 & 19.0 \\
\hline $10 / 13 / 2014$ & $8: 45$ & 94.0 & 1.18 & 0 & 1.180 & 18.5 \\
\hline
\end{tabular}


FX2 + Additive 1

\begin{tabular}{|c|c|c|c|c|c|c|}
\hline Date & Time & $\begin{array}{c}\text { Elapse } \\
\text { Time } \\
(\mathrm{hrs})\end{array}$ & $\begin{array}{c}\text { Measured } \\
\left(\mathrm{mg} \mathrm{Hg} / \mathrm{m}^{3}\right)\end{array}$ & Dilution & $\begin{array}{c}\mathrm{Hg} \\
\left(\mathrm{mg} / \mathrm{m}^{3}\right)\end{array}$ & Temp $\left({ }^{\circ} \mathrm{C}\right)$ \\
\hline $11 / 4 / 2014$ & $10: 30$ & 0.0 & 0.000 & 0 & 0.000 & 19.5 \\
\hline & $11: 00$ & 0.5 & 0.050 & 0 & 0.050 & 19.5 \\
\hline & $12: 30$ & 2.0 & 0.100 & 0 & 0.100 & 19.0 \\
\hline & $14: 30$ & 4.0 & 0.12 & 0 & 0.120 & 19.0 \\
\hline $11 / 5 / 2014$ & $10: 30$ & 24.0 & 0.250 & 0 & 0.250 & 20 \\
\hline $11 / 6 / 2014$ & $8: 00$ & 45.5 & 0.420 & 0 & 0.420 & 21.5 \\
\hline & $17: 00$ & 54.5 & 0.520 & 0 & 0.520 & 21.0 \\
\hline $11 / 10 / 2014$ & $12: 00$ & 145.5 & 0.450 & 0 & 0.450 & 21 \\
\hline
\end{tabular}

FX2 + Additive 2

\begin{tabular}{|c|c|c|c|c|c|c|}
\hline & Time & $\begin{array}{c}\text { Elapse } \\
\text { Time } \\
\text { Date }\end{array}$ & $\begin{array}{c}\text { Measured } \\
\left(\mathrm{mg} \mathrm{Hg} / \mathrm{m}^{3}\right)\end{array}$ & Dilution & $\begin{array}{c}\mathrm{Hg} \\
\left(\mathrm{mg} / \mathrm{m}^{3}\right)\end{array}$ & Temp $\left({ }^{\circ} \mathrm{C}\right)$ \\
\hline $10 / 15 / 2014$ & $10: 00$ & 0.0 & 0.000 & 0 & 0.000 & 23.0 \\
\hline & $10: 05$ & 0.1 & 0.100 & 0 & 0.100 & 23.0 \\
\hline & $10: 30$ & 0.5 & 0.14 & 0 & 0.140 & 23.0 \\
\hline & $12: 00$ & 2.0 & 0.27 & 0 & 0.270 & 24.5 \\
\hline & $15: 00$ & 5.0 & 0.53 & 0 & 0.530 & 24.5 \\
\hline $10 / 16 / 2014$ & $7: 30$ & 21.5 & 1.33 & 0 & 1.330 & 23.5 \\
\hline & $13: 00$ & 27.0 & 1.38 & 0 & 1.380 & 22.5 \\
\hline & $17: 00$ & 31.0 & 1.35 & 0 & 1.350 & 24.5 \\
\hline $10 / 20 / 2014$ & $8: 00$ & 118.0 & 1.19 & 0 & 1.190 & 23.5 \\
\hline
\end{tabular}


FX2 + Additive 3

\begin{tabular}{|c|c|c|c|c|c|c|}
\hline Date & Time & $\begin{array}{c}\text { Elapse } \\
\text { Time }(\mathrm{hrs})\end{array}$ & $\begin{array}{c}\text { Measured } \\
\left(\mathrm{mg} \mathrm{Hg} / \mathrm{m}^{3}\right)\end{array}$ & Dilution & $\begin{array}{c}\mathrm{Hg} \\
\left(\mathrm{mg} / \mathrm{m}^{3}\right)\end{array}$ & Temp $\left({ }^{\circ} \mathrm{C}\right)$ \\
\hline $11 / 11 / 2014$ & $9: 30$ & 0.0 & 0.000 & 0 & 0.000 & 21.5 \\
\hline & $10: 00$ & 0.5 & 0.100 & 0 & 0.100 & 23.0 \\
\hline & $12: 30$ & 3.0 & 0.230 & 0 & 0.230 & 22.0 \\
\hline & $15: 00$ & 5.5 & 0.310 & 0 & 0.310 & 21.0 \\
\hline & $17: 00$ & 7.5 & 0.360 & 0 & 0.360 & 22.0 \\
\hline $11 / 12 / 2014$ & $7: 30$ & 22.0 & 0.660 & 0 & 0.660 & 24.5 \\
\hline & $12: 30$ & 27.0 & 0.670 & 0 & 0.670 & 19.0 \\
\hline & $17: 00$ & 31.5 & 0.660 & 0 & 0.660 & 18.5 \\
\hline $11 / 13 / 2014$ & $8: 00$ & 46.5 & 0.530 & 0 & 0.530 & 17.5 \\
\hline & $4: 30$ & 55.0 & 0.520 & 0 & 0.520 & 16.5 \\
\hline $11 / 17 / 2014$ & $9: 00$ & 143.5 & 0.300 & 0 & 0.300 & 14.0 \\
\hline
\end{tabular}

FX2 + Additive 4

\begin{tabular}{|c|c|c|c|c|c|c|}
\hline & Time & $\begin{array}{c}\text { Elapse } \\
\text { Time }(\mathrm{hrs})\end{array}$ & $\begin{array}{c}\text { Measured } \\
\left(\mathrm{mg} \mathrm{Hg} / \mathrm{m}^{3}\right)\end{array}$ & Dilution & $\begin{array}{c}\mathrm{Hg} \\
\left(\mathrm{mg} / \mathrm{m}^{3}\right)\end{array}$ & Temp $\left({ }^{\circ} \mathrm{C}\right)$ \\
\hline $11 / 18 / 2014$ & $14: 00$ & 0.0 & 0.000 & 0 & 0.000 & 14.5 \\
\hline & $16: 00$ & 2.0 & 0.060 & 0 & 0.060 & 15.5 \\
\hline & $17: 00$ & 3.0 & 0.080 & 0 & 0.080 & 16.0 \\
\hline $11 / 19 / 2014$ & $13: 30$ & 23.5 & 0.340 & 0 & 0.340 & 17.0 \\
\hline & $17: 00$ & 27.0 & 0.370 & 0 & 0.370 & 17.5 \\
\hline $11 / 20 / 2014$ & $7: 30$ & 41.5 & 0.450 & 0 & 0.450 & 18.0 \\
\hline & $12: 30$ & 46.5 & 0.460 & 0 & 0.460 & 18.5 \\
\hline & $17: 00$ & 51.0 & 0.470 & 0 & 0.470 & 19.5 \\
\hline $11 / 24 / 2014$ & $8: 00$ & 138.0 & 0.410 & 0 & 0.410 & 18.5 \\
\hline
\end{tabular}


FX2 + Additive 5

\begin{tabular}{|c|c|c|c|c|c|c|}
\hline & Time & $\begin{array}{c}\text { Elapse } \\
\text { Time }(\mathrm{hrs})\end{array}$ & $\begin{array}{c}\text { Measured } \\
\left(\mathrm{mg} \mathrm{Hg} / \mathrm{m}^{3}\right)\end{array}$ & Dilution & $\begin{array}{c}\mathrm{Hg} \\
\left(\mathrm{mg} / \mathrm{m}^{3}\right)\end{array}$ & Temp $\left({ }^{\circ} \mathrm{C}\right)$ \\
\hline $12 / 2 / 2014$ & $11: 00$ & 0.0 & 0.000 & 0 & 0.000 & 19.5 \\
\hline & $11: 30$ & 0.5 & 0.040 & 0 & 0.040 & 19.5 \\
\hline & $13: 30$ & 2.5 & 0.090 & 0 & 0.090 & 19.5 \\
\hline & $17: 00$ & 6.0 & 0.160 & 0 & 0.160 & 20.3 \\
\hline $12 / 3 / 2014$ & $8: 00$ & 21.0 & 0.400 & 0 & 0.400 & 19.5 \\
\hline & $12: 00$ & 25.0 & 0.430 & 0 & 0.430 & 20.0 \\
\hline & $17: 00$ & 30.0 & 0.470 & 0 & 0.470 & 21.0 \\
\hline $12 / 4 / 2014$ & $7: 00$ & 44.0 & 0.530 & 0 & 0.530 & 21.0 \\
\hline & $13: 00$ & 50.0 & 0.530 & 0 & 0.530 & 18.5 \\
\hline & $17: 00$ & 54.0 & 0.480 & 0 & 0.480 & 18.5 \\
\hline $12 / 8 / 2014$ & $11: 00$ & 144.0 & 0.380 & 0 & 0.380 & 20.0 \\
\hline
\end{tabular}

Carboset (no additives)

\begin{tabular}{|c|c|c|c|c|c|c|}
\hline Date & Time & $\begin{array}{c}\text { Elapse } \\
\text { Time (hrs) }\end{array}$ & $\begin{array}{c}\text { Measured } \\
\left(\mathrm{mg} \mathrm{Hg} / \mathrm{m}^{3}\right)\end{array}$ & Dilution & $\begin{array}{c}\mathrm{Hg} \\
\left(\mathrm{mg} / \mathrm{m}^{3}\right)\end{array}$ & Temp ( $\left.{ }^{\circ} \mathrm{C}\right)$ \\
\hline $9 / 8 / 2015$ & $8: 00$ & 0.0 & 0.000 & 0 & 0.000 & 16.0 \\
\hline & $8: 30$ & 0.5 & 0.050 & 0 & 0.050 & 16.0 \\
\hline & $10: 30$ & 2.5 & 0.140 & 0 & 0.140 & 17.5 \\
\hline & $12: 30$ & 4.5 & 0.180 & 0 & 0.180 & 18.0 \\
\hline $9 / 9 / 2015$ & $7: 30$ & 23.5 & 0.480 & 0 & 0.480 & 18.5 \\
\hline & $16: 00$ & 32.0 & 0.470 & 0 & 0.470 & 21.0 \\
\hline $9 / 10 / 2015$ & $8: 30$ & 48.5 & 0.430 & 0 & 0.430 & 19.5 \\
\hline & $17: 00$ & 57.0 & 0.390 & 0 & 0.390 & 22.5 \\
\hline
\end{tabular}


Carboset + Additive 1

\begin{tabular}{|c|c|c|c|c|c|c|}
\hline Date & Time & $\begin{array}{c}\text { Elapse } \\
\text { Time }(\mathrm{hrs})\end{array}$ & $\begin{array}{c}\text { Measured } \\
\left(\mathrm{mg} \mathrm{Hg} / \mathrm{m}^{3}\right)\end{array}$ & Dilution & $\begin{array}{c}\mathrm{Hg} \\
\left(\mathrm{mg} / \mathrm{m}^{3}\right)\end{array}$ & Temp $\left({ }^{\circ} \mathrm{C}\right)$ \\
\hline $9 / 14 / 2014$ & $8: 30$ & 0.0 & 0.000 & 0 & 0.000 & 21.0 \\
\hline & $9: 00$ & 0.5 & 0.040 & 0 & 0.040 & 21.0 \\
\hline & $10: 00$ & 1.5 & 0.14 & 0 & 0.140 & 21.5 \\
\hline & $13: 00$ & 4.5 & 0.21 & 0 & 0.210 & 25.5 \\
\hline & $15: 00$ & 6.5 & 0.24 & 0 & 0.240 & 26.0 \\
\hline $9 / 15 / 2015$ & $8: 00$ & 23.5 & 0.5 & 0 & 0.500 & 23.0 \\
\hline & $14: 30$ & 30.0 & 0.44 & 0 & 0.440 & 22.0 \\
\hline & $17: 00$ & 32.5 & 0.42 & 0 & 0.420 & 23.0 \\
\hline $9 / 16 / 2015$ & $7: 30$ & 47.0 & 0.34 & 0 & 0.340 & 20.5 \\
\hline & $17: 00$ & 56.5 & 0.3 & 0 & 0.300 & 20.0 \\
\hline $9 / 17 / 2015$ & $9: 30$ & 73.0 & 0.27 & 0 & 0.270 & 18.0 \\
\hline & $16: 00$ & 79.5 & 0.25 & 0 & 0.250 & 19.0 \\
\hline
\end{tabular}

Encor Only (no additives)

\begin{tabular}{|c|c|c|c|c|c|c|}
\hline Date & Time & $\begin{array}{c}\text { Elapse } \\
\text { Time }(\mathrm{hrs})\end{array}$ & $\begin{array}{c}\text { Measured } \\
\left(\mathrm{mg} \mathrm{Hg} / \mathrm{m}^{3}\right)\end{array}$ & Dilution & $\begin{array}{c}\mathrm{Hg} \\
\left(\mathrm{mg} / \mathrm{m}^{3}\right)\end{array}$ & Temp $\left({ }^{\circ} \mathrm{C}\right)$ \\
\hline $10 / 5 / 2015$ & $10: 00$ & 0.0 & 0.000 & 0 & 0.000 & 15.5 \\
\hline & $10: 30$ & 0.5 & 0.080 & 0 & 0.080 & 15.5 \\
\hline & $12: 30$ & 2.5 & 0.240 & 0 & 0.240 & 16.0 \\
\hline & $17: 00$ & 7.0 & 0.350 & 0 & 0.350 & 17.5 \\
\hline $10 / 6 / 2015$ & $10: 00$ & 24.0 & 0.500 & 0 & 0.500 & 15.5 \\
\hline & $15: 00$ & 29.0 & 0.480 & 0 & 0.480 & 18.0 \\
\hline & $17: 00$ & 31.0 & 0.490 & 0 & 0.490 & 18.5 \\
\hline $10 / 7 / 2015$ & $10: 00$ & 48.0 & 0.460 & 0 & 0.460 & 16.0 \\
\hline & $14: 00$ & 52.0 & 0.410 & 0 & 0.410 & 17.5 \\
\hline & $17: 00$ & 55.0 & 0.410 & 0 & 0.410 & 18.5 \\
\hline $10 / 8 / 2015$ & $10: 00$ & 72.0 & 0.360 & 0 & 0.360 & 16.5 \\
\hline & $13: 30$ & 75.5 & 0.350 & 0 & 0.350 & 19.5 \\
\hline & $17: 00$ & 79.0 & 0.320 & 0 & 0.320 & 20.5 \\
\hline
\end{tabular}


Encor + Additive 1

\begin{tabular}{|c|c|c|c|c|c|c|}
\hline Date & Time & $\begin{array}{c}\text { Elapse } \\
\text { Time }(\mathrm{hrs})\end{array}$ & $\begin{array}{c}\text { Measured } \\
\left(\mathrm{mg} \mathrm{Hg} / \mathrm{m}^{3}\right)\end{array}$ & Dilution & $\begin{array}{c}\mathrm{Hg} \\
\left(\mathrm{mg} / \mathrm{m}^{3}\right)\end{array}$ & Temp $\left({ }^{\circ} \mathrm{C}\right)$ \\
\hline $9 / 28 / 2015$ & $8: 00$ & 0.0 & 0.000 & 0 & 0.000 & 21.0 \\
\hline & $8: 30$ & 0.5 & 0.110 & 0 & 0.110 & 21.0 \\
\hline & $10: 30$ & 2.5 & 0.220 & 0 & 0.220 & 21.5 \\
\hline & $12: 30$ & 4.5 & 0.290 & 0 & 0.290 & 22.0 \\
\hline & $16: 00$ & 8.0 & 0.390 & 0 & 0.390 & 22.0 \\
\hline & $17: 00$ & 9.0 & 0.420 & 0 & 0.420 & 22 \\
\hline $9 / 29 / 2015$ & $7: 30$ & 23.5 & 0.530 & 0 & 0.530 & 21.5 \\
\hline & $12: 00$ & 28.0 & 0.510 & 0 & 0.510 & 21 \\
\hline & $17: 00$ & 33.0 & 0.520 & 0 & 0.520 & 21.5 \\
\hline $9 / 30 / 2015$ & $8: 00$ & 48.0 & 0.460 & 0 & 0.460 & 21.5 \\
\hline & $17: 00$ & 57.0 & 2.640 & 0 & 2.640 & 22.0 \\
\hline
\end{tabular}

Stripcoat TLC Free Only (no additives)

\begin{tabular}{|c|c|c|c|c|c|c|}
\hline Date & Time & $\begin{array}{c}\text { Elapse } \\
\text { Time }(\mathrm{hrs})\end{array}$ & $\begin{array}{c}\text { Measured } \\
\left(\mathrm{mg} \mathrm{Hg} / \mathrm{m}^{3}\right)\end{array}$ & Dilution & $\begin{array}{c}\mathrm{Hg} \\
\left(\mathrm{mg} / \mathrm{m}^{3}\right)\end{array}$ & Temp $\left({ }^{\circ} \mathrm{C}\right)$ \\
\hline $10 / 12 / 2015$ & $8: 30$ & 0.0 & 0.000 & 0 & 0.000 & 16.0 \\
\hline & $9: 00$ & 0.5 & 0.160 & 0 & 0.160 & 16.0 \\
\hline & $12: 30$ & 4.0 & 0.250 & 0 & 0.250 & 16.0 \\
\hline & $14: 30$ & 6.0 & 0.310 & 0 & 0.310 & 21.5 \\
\hline & $17: 00$ & 8.5 & 0.410 & 0 & 0.410 & 21.5 \\
\hline $10 / 13 / 2015$ & $7: 30$ & 23.0 & 0.680 & 0 & 0.680 & 21.5 \\
\hline & $11: 00$ & 26.5 & 0.770 & 0 & 0.770 & 22.5 \\
\hline & $15: 30$ & 31.0 & 0.900 & 0 & 0.900 & 18.0 \\
\hline $10 / 14 / 2015$ & $8: 30$ & 48.0 & 1.120 & 0 & 1.120 & 23.5 \\
\hline & $17: 00$ & 56.5 & 1.140 & 0 & 1.140 & 19.0 \\
\hline $10 / 15 / 2015$ & $8: 30$ & 72.0 & 1.200 & 0 & 1.200 & 25.5 \\
\hline & $13: 00$ & 76.5 & 1.240 & 0 & 1.240 & 20.5 \\
\hline $10 / 19 / 2015$ & $8: 30$ & 168.0 & 1.160 & 0 & 1.160 & 19.0 \\
\hline & $16: 00$ & 175.5 & 1.160 & 0 & 1.160 & 20.0 \\
\hline
\end{tabular}


Stripcoat TLC Free + Additive 1

\begin{tabular}{|c|c|c|c|c|c|c|}
\hline & Date & $\begin{array}{c}\text { Elapse } \\
\text { Time }(\mathrm{hrs})\end{array}$ & $\begin{array}{c}\text { Measured } \\
\left(\mathrm{mg} \mathrm{Hg} / \mathrm{m}^{3}\right)\end{array}$ & Dilution & $\begin{array}{c}\mathrm{Hg} \\
\left(\mathrm{mg} / \mathrm{m}^{3}\right)\end{array}$ & Temp $\left({ }^{\circ} \mathrm{C}\right)$ \\
\hline $10 / 20 / 2015$ & $8: 30$ & 0.0 & 0.000 & 0 & 0.000 & 23.5 \\
\hline & $9: 00$ & 0.5 & 0.250 & 0 & 0.250 & 22.0 \\
\hline & $11: 30$ & 3.0 & 0.540 & 0 & 0.540 & 20.5 \\
\hline & $15: 30$ & 7.0 & 0.630 & 0 & 0.630 & 19.5 \\
\hline $10 / 21 / 2015$ & $8: 30$ & 24.0 & 0.730 & 0 & 0.730 & 24.0 \\
\hline & $13: 00$ & 28.5 & 0.730 & 0 & 0.730 & 24.5 \\
\hline & $17: 00$ & 37.0 & 0.710 & 0 & 0.710 & 19.5 \\
\hline $10 / 22 / 2015$ & $8: 30$ & 48.0 & 0.630 & 0 & 0.630 & 25.5 \\
\hline & $17: 00$ & 56.5 & 0.590 & 0 & 0.590 & 24.0 \\
\hline $10 / 26 / 2015$ & $8: 30$ & 144 & 0.200 & 0 & 0.200 & 23.0 \\
\hline
\end{tabular}

